\title{
Pengembangan aplikasi buku penghubung berbasis web sebagai media interaksi sekolah - orang tua
}

\author{
Heri Kuswanto ${ }^{*}$, Baiq Desi Dwi Arianti² \\ 1 Program Studi Pendidikan Informatika, Universitas Hamzanwadi \\ *heriku@hamzanwadi.ac.id
}

\begin{abstract}
Abstrak
Buku penghubung merupakan salah satu instrumen penunjang mekanisme komunikasi guru dan orang tua. Peran teknologi dianggap mampu menunjang keterlibatan orang tua dalam proses belajar siswa. Namun, penerapan teknologi informasi di Sekolah yang ada di pedesaan memiliki kompleksitas lebih tinggi dibandingkan dengan di perkotaan. Salah satu penyebabnya adalah kegunaan dan kemudahan dari teknologi informasi tersebut, sering kali kurang sesuai dengan karakteristik pengguna. Penelitian ini menggunakan metode penelitian dan pengembangan $(R \& D)$ dengan pendekatan model waterfall yang difokuskan pada upaya menghasilkan prototype produk. Tahapan penelitian dan pengembangan ini meliputi communication, planning, modelling, construction, dan deployment. Produk pengembangan berbasis web menggunakan konsep desain pattern MVC dengan framework YII melalui tahapan pengujian unit test dan analisis kualitas menggunakan standar ISO25010. Hasil dari penelitian dan pengembangan ini berupa prototype aplikasi Buku penghubung sebagai proof of concept terhadap pendekatan yang digunakan.
\end{abstract}

Kata kunci: buku penghubung, waterfall, aplikasi web, karakteristik pengguna

\begin{abstract}
Communication book is one of supporting instrument of communication mechanism of teacher and parents considered not yet effective. Thus, it is necessary to develop a communication book in the digital environment as a solution to the problem. This study aims to develop communication book applications as a medium of communication between teachers and parents. This research uses research and development $(R \& D)$ method with waterfall model approach that focused on efforts to produce a prototype of the product. Stages of research and development include communication, planning, modeling, construction, and deployment. Web-based development product using MVC design pattern concept with YII framework through the testing unit and ISO25010 standard quality. The result of this research and development is a prototype of communication book application as a proof of concept towards the approach used.
\end{abstract}

Keywords: comunication book, user characteristic, diffusion of innovation theory

\section{Pendahuluan}

Salah satu faktor penting yang mempengaruhi perkembangan siswa adalah peran orang tua. Orang tua memainkan peran yang sangat penting dalam menyediakan kesempatan belajar di rumah dan dalam menghubungkan apa yang anaknya pelajari di sekolah dengan apa yang ada di sekitarnya [1]. Pentingnya keterlibatan orang tua dalam pendidikan untuk membantu siswa dalam belajar, membangun karakter yang mendukung sekolah, guru, dan lingkungan di sekitar mereka; serta mengembangkan kemampuan beradaptasi terhadap dampak globalisasi [2]. 
Kebanyakan orang tua kesulitan membantu anaknya belajar di rumah [3]. Penelitian Rahman [4] menunjukkan bahwa sebenarnya orang tua ingin terlibat langsung dalam peningkatan kompetensi peserta didik tetapi beberapa kendala, seperti waktu, kesempatan, kompetensi, dan pengalaman mereka berbeda serta kurikulum yang selalu berubah dari waktu ke waktu. Oleh karena itu, sekolah perlu memfasilitasi keterlibatan orang tua.

Tujuan komunikasi serta saluran komunikasi yang kurang jelas dianggap sebagai faktor yang menyebabkan terjadinya gap antara guru dan orang tua yang berakibat pada rendahnya keterlibatan orang tua pada proses belajar siswa [5]. Beberapa instrumen yang digunakan oleh guru dan orang tua untuk berkomunikasi adalah dengan menggunakan buku penghubung, surat, aplikasi pesan instan, grup media sosial dan website sekolah.

Penggunaan buku penghubung dirasa belum efektif sebagai salah satu instrumen komunikasi antara guru dan orang tua sebagaimana pendataan yang dilakukan terhadap 386 peserta didik di SDS Gembala Baik I Pontianak, terdapat 107 peserta didik atau sebesar $27,72 \%$ yang tidak membawa buku penghubung meskipun sudah diharuskan untuk membawa [6]. Sedangkan komunikasi melalui pesan instan seperti whatsapp messenger, blackberry messenger, dan grup media sosial dianggap belum optimal karena aplikasi tersebut tidak terintegrasi dengan basis data di sekolah. Sehingga komunikasi yang terjadi adalah komunikasi satu arah.

Perkembangan teknologi informasi meliputi berbagai bidang termasuk bidang pendidikan. Inovasi teknologi pendidikan di terus mengalami peningkatan, hal ini terlihat dari banyaknya pemanfaatan teknologi informasi sebagai media pembelajaran. Namun, inovasi teknologi informasi belum sepenuhnya di eksplorasi dengan optimal, terutama untuk meningkatkan keterlibatan orang tua dalam proses belajar [7]. Berbagai inovasi teknologi pendidikan tersebut belum sepenuhnya dapat diadopsi oleh sekolah terutama sekolah yang berada di pedesaan. Hal tersebut terjadi karena inovasi yang ada belum sesuai dengan kebutuhan. Menurut Roger [8] Kegagalan adopsi teknologi dapat terjadi karena inovasi tersebut tidak sesuai dengan kebutuhan warga sekolah, pengembang teknologi informasi gagal menggunakan saluran komunikasi yang tepat, tidak memperhitungkan waktu implementasi dengan tepat, atau tidak memahami sistem sosial yang berlaku. Studi [9]menjelaskan bahwa teknologi informasi perlu memperhatikan beberapa aspek pada inovasi tersebut, yakni: (1) komunikasi (2) dapat membantu sekolah untuk mengerti dan melayani warga sekolah; (3) membantu sekolah secara kontinu untuk meningkatkan proses secara internal. Oleh karena itu, pengembangan perangkat lunak yang 
Infotek : Jurnal Informatika dan Teknologi

Vol. 5 No. 1, Januari 2022

Hal. 167-178

e-ISSN 2614-8773

DOI : $10.29408 /$ jit.v5i1.4742

Link : https://dx.doi.org/10.29408/jit.v5i1.4742

menyediakan komunikasi dua arah perlu dikembangkan berdasarkan karakteristik pengguna di suatu daerah. Menurut Heath, Maghribi, \& Carr [10] pengembangan perangkat lunak berdasarkan teori difusi inovasi dan komunikasi dua arah cocok digunakan sebagai alat komunikasi antara sekolah dan orang tua. Instrumen komunikasi berbasis teknologi informasi diperlukan sebagai media komunikasi antara guru dan orang tua dalam menjalin kemitraan yang harmonis agar tujuan pendidikan dapat tercapai. Konsep instrumen tersebut dapat menggunakan konsep yang sudah ada misalnya penggunaan buku penghubung berbasis kertas ditingkatkan menjadi buku penghubung berbasis digital.

\section{Tinjauan Pustaka}

\subsection{Penelitian Terkait}

- Kajian yang berjudul Integrated Parent Informtion System (SMIB) to Increase Parental in Children's Learning Process in Malaysian Primary School. Kajian ini mengembangkan desain aplikasi SMIB sebagai framework untuk mendukung keterlibatan orang tua dalam proses belajar mengajar anaknya [11].

- Kajian selanjutnya yang berjudul "Pengembangan Sistem Informasi Distribusi Informasi Sekolah Melalui SMS Gateway dengan Zachman Framework" menghasilkan produk sistem informasi distribusi untuk menyebarkan informasi sekolah melalui SMS gateway. Kajian ini menekankan pada pendekatan Zachman Framework yang di uji coba di SDS Gembala Baik I Pontianak, kelemahannya terdapat pada kebutuhan user. Orang tua sebagai penerima informasi yang didistribusikan melalui sistem informasi tersebut tidak dapat memberikan informasi kepada guru maupun sekolah tentang proses belajar anaknya di rumah, begitu sebaliknya guru tidak dapat memberikan catatan maupun tutorial sebagai arahan untuk orang tua dalam mendampingi anaknya belajar di rumah [6].

- Kajian selanjutnya berjudul Implication of Information and Communication Technologies (ICT) for School-Home Communication. Hasil kajiannya yakni, mengembangkan model komunikasi antara orang tua dan sekolah, dengan pemanfaatan teknologi informasi (ICT) berdasarkan twoway communication symmetry sebagai framework yang dapat digunakan untuk membangun komunikasi antara sekolah dan orang tua secara umum[10] .

- Kajian dengan judul Electronic Booklet: School - Family Collaboration in Digital Environments. Kajian ini menghasilkan produk berupa electronik booklet sebagai pendukung komunikasi antara orang tua, 
organisasi sekolah, dan sekolah. Produk ini masih sebatas prototype dan belum ada kajian mengenai dampak implementasi dari adopsi teknologi ini [7].

\subsection{Landasan Teori}

Buku penghubung disebut juga sebagai buku komunikasi (communication book). Buku komunikasi dapat diartikan sesuatu yang berbeda oleh orang yang berbeda, di beberapa sekolah menggunakan buku komunikasi untuk berbagi informasi kepada orang tua tentang peserta didik setiap hari [12] .

Meskipun istilah tersebut berbeda namun memiliki fungsi yang sama yakni banyak guru menggunakan buku penghubung untuk membagikan informasi dengan orang tua, terutama bagi peserta didik yang memiliki kebutuhan pembelajaran khusus [13]. Pendapat senada juga mengatakan bahwa buku penghubung atau jurnal harian adalah buku yang bolak-balik dari rumah ke sekolah, dan biasa digunakan dalam pendidikan khusus [14] .

Buku komunikasi dapat dikatan sebagai sebuah sistem informasi. Karena secara teori penerapan sebuah sistem informasi memang tidak harus menggunakan komputer dalam kegiatannya[15]. Buku komunikasi yang telah dikembangkan sebagai sistem informasi dalam lingkungan digital disebut e-booklet merupakan evolusi alami buku penghubung berbasis kertas dan dikembangkan pada lingkungan grafis, diterjemahkan dalam bahasa berorientasi objek [7]. Oleh karena itu, pengembangan buku penghubung atau buku komunikasi pada lingkungan digital dinamakan aplikasi communication book yang dikembangkan menggunakan teknologi web pada penelitian ini. Produk pengembangan teknologi web dapat berupa system informasi berbasis web yakni sebuah sarana pada sistem komputerisasi yang dirancang sesuai dengan kebutuhan dengan tujuan mempermudah, mempercepat, dan pengolahan data yang akurat [16]. Desain pattern yang paling banyak digunakan saat ini untuk mengembangkan aplikasi berbasis web adalah pendekatan Model View Controller [17].

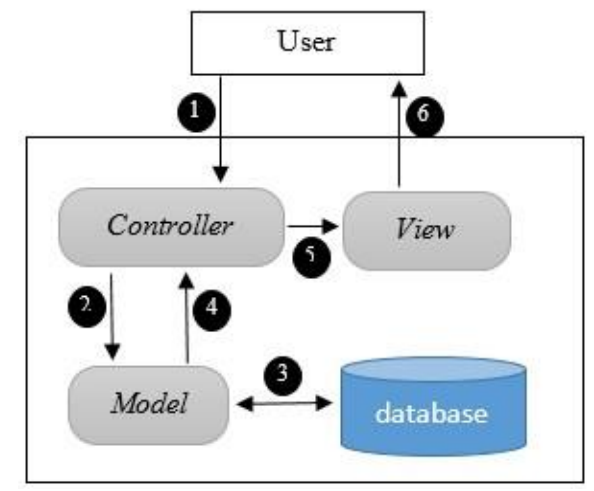

Gambar 1. Skema Model-View-Controll [18] Yii merupakan singkatan dari "Yes it is" sebagai salah satu framework PHP menggunakan pendekatan Model View Controller (MVC) yang dikembangkan oleh Yii Software LLC.

Difusi yakni proses di mana suatu inovasi dikomunikasikan melalui saluran tertentu dalam jangka waktu tertentu di antara anggota suatu sistem sosial. Sedangkan inovasi sebagai suatu 
gagasan, praktik, atau benda yang dianggap/dirasa baru oleh individu [8] .

Unsur-unsur difusi inovasi terdiri dari inovasi, saluran komunikasi, waktu, dan sistem sosial. Unsur inovasi memiliki lima karakteristik yaitu: relative advantage, compatibility, complexity, triability, dan obsevability. Saluran komunikasi terdiri dari dua jenis yakni komunikasi massa dan komunikasi personal. Waktu mempengaruhi bagaimana sebuah ide dapat disampaikan kepada anggota organisasi/kelompok. Sistem sosial memiliki struktur sosial, individu atau kelompok, dan norma-norma tertentu.

Roger [8] mendefinisikan kategori pengadopsi sebagai klasifikasi dari anggota dalam suatu sistem sosial berdasarkan keinovatifan. Klasifikasi merupakan tingkat kecepatan dalam mengadopsi suatu inovasi yang terbagi dalam 5 kategori yaitu: perintis (innovator), pelopor (early adopters), penganut dini atau mayoritas awal (early mayority), penganut akhir atau mayoritas akhir (late mayority), dan kolot (laggard).

Teori difusi inovasi tersebut sudah dikaji dalam berbagai bidang yang mencakup ide, praktik, program dan teknologi [19]. Oleh karena itu, konsep difusi dapat dioperasionalkan dalam proyek untuk mempengaruhi tingkat adopsi inovasi dengan melambatkan atau lebih umum lagi dengan mempercepat penyebarannya [20]. Dengan demikian, pengembangan teknologi informasi cukup bergantung pada pemahaman bagaimana inovasi tersebut dapat diadopsi.

Roger [8] membagi karakteristik pengguna menjadi 2 karakteristik yaitu karakteristik berdasarkan kepuasan pengguna (user satisfaction) dan karakteristik berdasarkan resistansi pengguna (user resistance). Kepuasan pengguna berarti sikap terhadap penggunaan aplikasi komputer tertentu yang berinteraksi dengannya [21]. Resistansi pengguna (user resistance) mengacu pada keengganan sistem operasi sebagai reaksi berlawanan terhadap perubahan yang diperkirakan. Strategi utama untuk menurunkan resistensi adalah pendidikan pengguna, komunikasi, partisipasi pengguna, bimbingan dan penjelasan tentang manfaat yang diharapkan dari sistem [22].

\section{Metode Penelitian}

\subsection{Model Pengembangan}

Metode penelitian yang akan digunakan adalah penelitian dan pengembangan atau Research and Development (R\&D). Penelitian dan pengembangan adalah suatu proses atau langkah-langkah untuk mengembangkan suatu produk baru atau menyempurnakan produk yang telah ada, yang dapat dipertanggungjawabkan [23].

\subsection{Prosedur Pengembangan}

Prosedur pengembangan dalam penelitian ini akan disesuaikan dengan langkah-langkah 
Infotek : Jurnal Informatika dan Teknologi

Vol. 5 No. 1, Januari 2022

Hal. 167-178

e-ISSN 2614-8773

DOI : 10.29408/jit.v5i1.4742

Link : https://dx.doi.org/10.29408/jit.v5i1.4742

berdasarkan model prosedural yang ditentukan, yakni mengacu pada model waterfall atau classic life cycle, sebagaimana yang dikemukakan Pressman [24] bahwa model pengembangan waterfall menggunakan pendekatan yang sistematis dan berurutan pada pengembangan software. Sebagaimana tahapan-tahapannya dijelaskan pada Error! Reference source not found.:

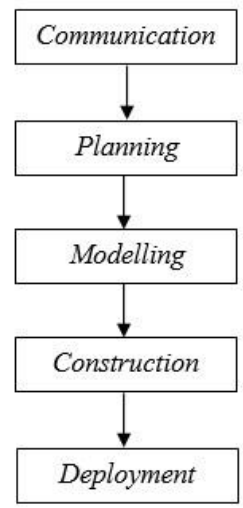

Gambar 2. Modifikasi Model Waterfall [24]

\subsection{Desain Uji Coba}

Pengujian produk dapat dilakukan dengan pengujian unit test. Selain pengujian unit, pengujian kualitas produk juga dilakukan terhadap perangkat lunak berdasarkan standar ISO 25010 meliputi funtionality, reliability, efficiency, maintainability, compatibility, security, usability, dan portability.

Subjek penelitian ini adalah warga sekolah yang terdiri guru, tenaga kependidikan, dan orang tua siswa. Uji coba lapangan akan dilaksanakan di SMP Negeri 1 Selong sebagai populasi. Karena subjeknya cukup luas maka penentuan sampelnya menggunakan nonprobability sampling.

\subsection{Teknik Pengumpulan Data}

Teknik pengumpulan data dapat dilakukan dengan wawancara (interview), kuesioner (angket), observasi (pengamatan), dan gabungan ketiganya.

\subsection{Teknik Analisis Data}

Teknik analisis data dilakukan dengan menggunakan teknik kuantitatif deskriptif. Menurut Arikunto [25], data kuantitatif yang berwujud angka-angka hasil perhitungan atau pengukuran dapat diproses dengan cara dijumlah, dibandingkan dengan jumlah yang diharapkan dan diperoleh persentase.

Tabel 1. Persentase Kelayakan

\begin{tabular}{ccc}
\hline Persentase (\%) & Skala Nilai & Interpretasi \\
\hline $76-100$ & 4 & Sangat Layak \\
$51-75$ & 3 & Layak \\
$26-50$ & 2 & Kurang Layak \\
$0-25$ & 1 & Tidak Layak \\
\hline
\end{tabular}

\section{Hasil dan Pembahasan}

\subsection{Communication}

Analisis karakteristik pengguna didasarkan pada hasil wawancara tertutup yang dilakukan terhadap 30 orang responden yang terdiri dari 1 orang kepala sekolah, 12 orang guru, 2 orang tenaga kependidikan, dan 15 orang tua/wali. Wawancara dilakukan dengan memberikan lembar wawancara yang berisi pertanyaanpertanyaan serta catatan kecil terkait dengan wawancara tersebut untuk melengkapi hasil 
Infotek : Jurnal Informatika dan Teknologi

Vol. 5 No. 1, Januari 2022

Hal. 167-178

e-ISSN 2614-8773

DOI : 10.29408/jit.v5i1.4742

Link : https://dx.doi.org/10.29408/jit.v5i1.4742

wawancara. Hasil wawancara tersebut dapat ditunjukkan pada Error! Reference source not found.:

Tabel 2. Karakteristik Pengguna

\begin{tabular}{|c|c|c|}
\hline & Sekolah & Orang tua \\
\hline $\begin{array}{l}\text { Pilihan } \\
\text { Komunikasi }\end{array}$ & $\begin{array}{l}\text { Sosial Media, } \\
\text { Pesan Instan, } \\
\text { Website } \\
\text { Sekolah, } \\
\text { SMS, Surat }\end{array}$ & $\begin{array}{l}\text { Sosial Media, } \\
\text { Pesan Instan, } \\
\text { SMS }\end{array}$ \\
\hline $\begin{array}{l}\text { ICT yang } \\
\text { tersedia }\end{array}$ & $\begin{array}{l}\text { Lab. } \\
\text { Komputer } \\
\text { Laptop, } \\
\text { Internet, } \\
\text { Gadget }\end{array}$ & $\begin{array}{l}\text { Komputer/laptop } \\
\text { Smartphone }\end{array}$ \\
\hline $\begin{array}{l}\text { Karakteristi } \\
\text { k Adopsi }\end{array}$ & $\begin{array}{l}\text { Penganut dini } \\
\text { (early } \\
\text { mayority) }\end{array}$ & $\begin{array}{l}\text { Pengguna dini } \\
\text { (early mayority) }\end{array}$ \\
\hline Pendidikan & S1 dan S2 & $\begin{array}{l}\text { SMP, SMA, S1, } \\
\text { dan S2 }\end{array}$ \\
\hline $\begin{array}{l}\text { Status } \\
\text { Ekonomi }\end{array}$ & PNS & $\begin{array}{l}\text { PNS, TNI/Polri, } \\
\text { Petani, Swasta }\end{array}$ \\
\hline Organisasi & $\begin{array}{l}\text { Kepala } \\
\text { Sekolah }\end{array}$ & Komite Sekolah \\
\hline
\end{tabular}

Tabel 2 tersebut menunjukkan bahwa sekolah dan orang tua memiliki berbagai pilihan untuk berkomunikasi yaitu sosial media, pesan instan, website sekolah, SMS, dan surat. Ketersediaan ICT berupa lab komputer, laptop, gadget, dan internet akan memudahkan pengadopsian aplikasi perangkat lunak yang dikembangkan. Tingkat pendidikan, status ekonomi yang cukup variatif dapat menyebabkan resistansi pengguna yang cukup besar.

Kepala sekolah sebagai organisasi pendidik dan tenaga kependidikan di sekolah dan komite sekolah sebagai organisasi orang tua memiliki pengaruh yang cukup kuat. Faktor Opinion leader berpengaruh terhadap karakteristik adopsi sebagai penganut dini suatu inovasi di SMPN 1 Selong. Pemanfaatan ICT untuk pembelajaran sudah dilakukan sejak lama menggunakan aplikasi Edmodo. Penggunaan edmodo terbatas pada bentuk laporan, dan orang tua tidak dapat berkomunikasi secara personal dengan guru.

Permasalahan yang sering muncul adalah terkait dengan permasalahan akademik siswa. Terjadi miss communication antara guru dan orang tua di SMPN 1 Selong. Sebagaimana ungkapan guru sebagai mengatakan:

“...kalau ada permasalahan terkait nilai, orang tua langsung melaporkan hal tersebut ke sekolah tanpa berkomunikasi dengan kami (guru)..."

Hal tersebut terjadi karena adanya resistansi pada sistem sosial di SMPN 1 Selong.

\subsection{Planning}

Tahap ini merencanakan waktu yang diperlukan selama proses pengembangan aplikasi communication book mulai dari tahap communication, planning, modelling, construction, dan deployment yakni kurang lebih tujuh bulan dari bulan Februari sampai dengan bulan Agustus 2021. Pengembangan aplikasi communication book ini juga memerlukan biaya yang cukup terjangkau.

\subsection{Modelling}

Tahapan modelling terdiri dari analisis dan desain. Analisis kebutuhan terhadap pengembangan sistem Communication Book sebagai media 
informasi aktivitas siswa terkait akademik dan non akademik di sekolah diperlukan analisis konten mengenai informasi apa saja yang disampaikan. Sementara untuk analisis operasional terdiri dari spesifikasi perangkat keras (hardware) dan perangkat lunak (software).

Desain aplikasi communication book secara umum desain aplikasi menggunakan Unified Modelling Language (UML). UML memiliki diagram seperti use case diagram, activity diagram, sequence diagram yang secara umum menggambarkan rancangan dan dokumentasi perangkat lunak sesuai standar industri [26]. Selain alur kerja sistem rancangan basis data, rancangan antar muka (interface), dan rancangan prosedural sebagai berikut:

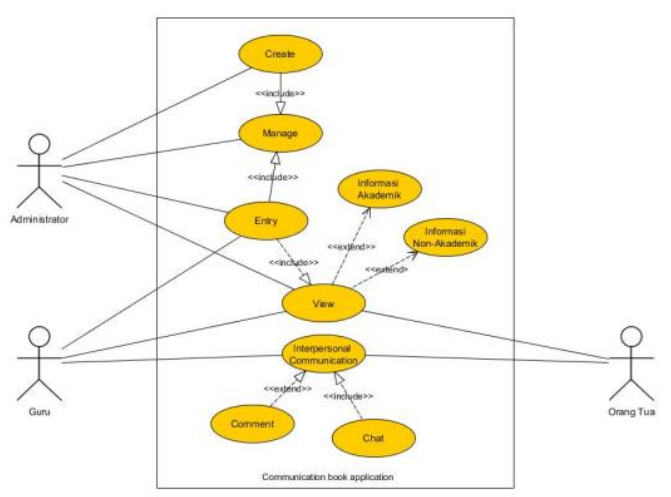

Gambar 3. Use case diagram aplikasi

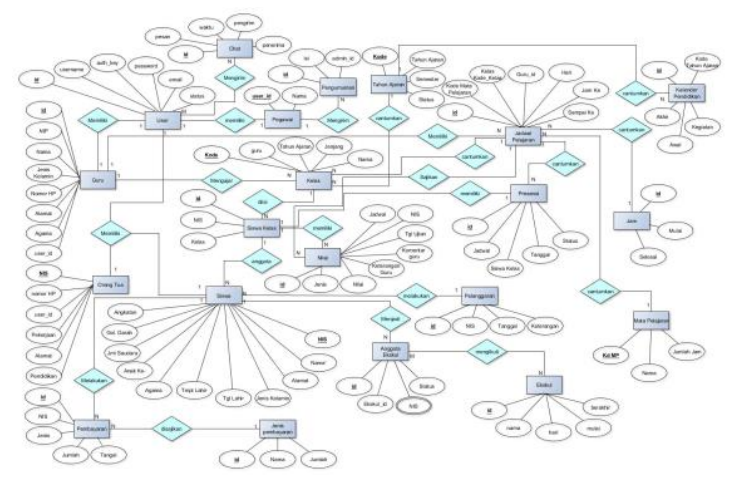

Gambar 4. Rancangan basis data

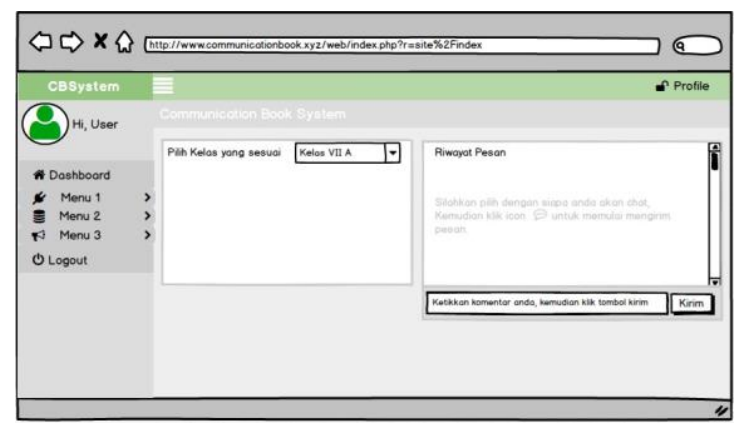

Gambar 5. Rancangan antar muka

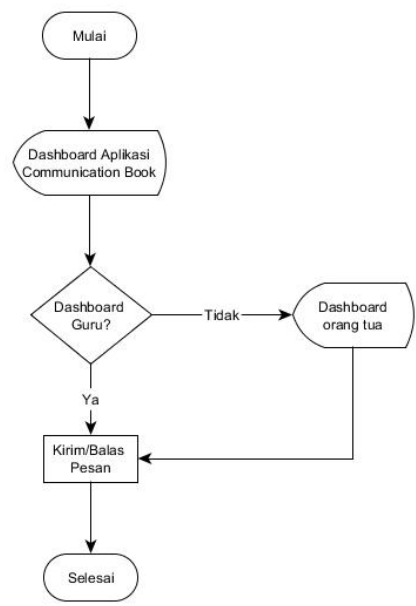

Gambar 6. Rancangan prosedural

Berdasarkan rancangan yang dibuat diharapkan beberapa fitur standar sebagai berikut:

1. Administrator dapat membuat, meng-entry, menampilkan, serta me-manage secara umum fungsi yang terdapat aplikasi communication book.

2. Guru dapat melihat informasi akademik dan non-akademik, meng-entry beberapa fungsi aplikasi communication book, dan melakukan komunikasi secara personal dengan aktor orang tua melalui fitur chat dan komentar. 
Infotek : Jurnal Informatika dan Teknologi

Vol. 5 No. 1, Januari 2022

Hal. 167-178

e-ISSN 2614-8773

Link : https://dx.doi.org/10.29408/jit.v5i1.4742

3. Orang tua hanya dapat melihat informasi akademik dan non-akademik, serta melakukan komunikasi personal dengan guru melalui fitur chat dan komentar.

\subsection{Construction}

Tahap construction ini terdiri dari implementasi dan pengujian (testing). Implementasi aplikasi communication book mengikuti desain yang sudah dirancang. Hasil implementasi aplikasi communication book dapat dilihat pada Error!

Reference source not found:

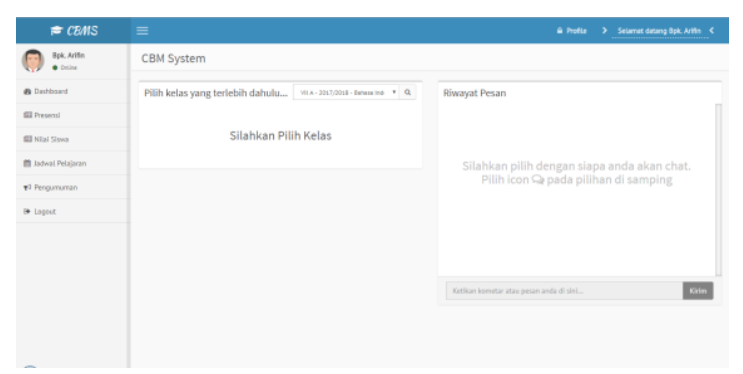

Gambar 7. Implementasi Aplikasi

Pengujian kualitas produk menggunakan standar ISO25010 meliputi functionality, eficiency, reliability, maintainability, compatibility, security, usability, dan portability.

Pengujian aspek functionality diperoleh dengan menggunakan angket berupa checklist "ya" bernilai 1 dan "tidak" bernilai 0 pada masingmasing pernyataan fungsionalitas sebanyak 38 item. Angket tersebut disebar kepada 2 orang ahli pengembangan aplikasi berbasis web. Hasil pengujian functionality diperoleh skor sebesar 76 atau $100 \%$ yang berarti bahwa aplikasi berfungsi dengan sangat layak.
Pengujian eficiency dilakukan dengan menggunakan bantuan aplikasi GTmetrix. Hasil pengujiannya dapat dilihat pada Gambar 8 berikut:

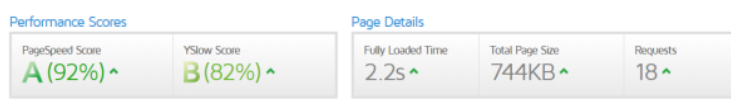

Gambar 8. Hasil pengujian efficiency

Gambar 8 menunjukkan perolehan performance score grade A dalam persentase sebesar $92 \%$, dengan rata-rata kecepatan loading membutuhkan waktu 2,2 detik. Hasil ini menunjukkan bahwa pengujian aspek efficiency memiliki rating tinggi yang dapat diartikan bahwa aplikasi communication book sangat efisien.

Pengujian reliability menggunakan bantuan software WAPT 8.1 memperhatikan parameter session, pages, dan hits dengan skenario 1-20 user secara simultan selama 2 menit dengan asumsi terdapat 2 user setiap 30 detik. Hasil pengujian dapat dilihat pada Tabel 3 berikut: Tabel 3. Hasil pengujian reliability

\begin{tabular}{ccc}
\hline Aspek pengamatan & Success & Failed \\
\hline Session & 0 & 14 \\
Pages & 140 & 14 \\
Hits & 335 & 14 \\
\hline
\end{tabular}

Tabel 3 menunjukkan bahwa terdapat beberapa parameter yang mengalami kegagalan dalam pengujian dengan angka yang relatif kecil, sehingga aplikasi mampu bertahan dengan kinerjanya dalam skenario yang diterapkan.

Pengujian maintainability menggunakan ukuranukuran (metric) pada operasional yang dilakukan. 
Pengujian maintainability memperhatikan tiga aspek yaitu: instrumentation, consistensy, dan simplicity. Hasil pengujian menunjukkan bahwa semua aspek yang amati memenuhi kriteria yang diinginkan.

Pengujian compatibility menggunakan bantuan software SortSite. Hasil pengujian dapat dilihat pada gambar berikut:

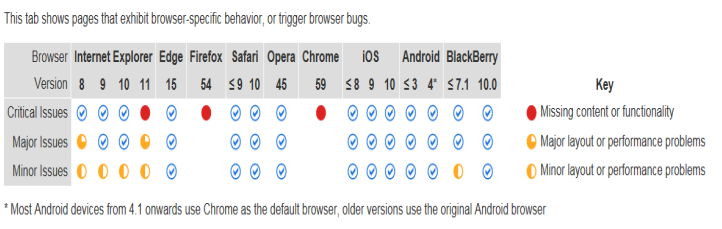

Gambar 9. Hasil pengujian compatibility

Gambar 9 menunjukkan bahwa sebagian besar browser pada desktop maupun mobile dapat berjalan dengan baik meski terdapat beberapa masalah pada konten, fungsi, dan layout. Tidak disarankan menjalankan aplikasi ini menggunakan browser Internet Explore 11, Mozilla Firefox 54, dan Chrome 59.

Pengujian security menggunakan bantuan software Acunetix Web Vulnerability Scanner 9.5. Hasil pengujian security dapat dilihat pada gambar berikut:

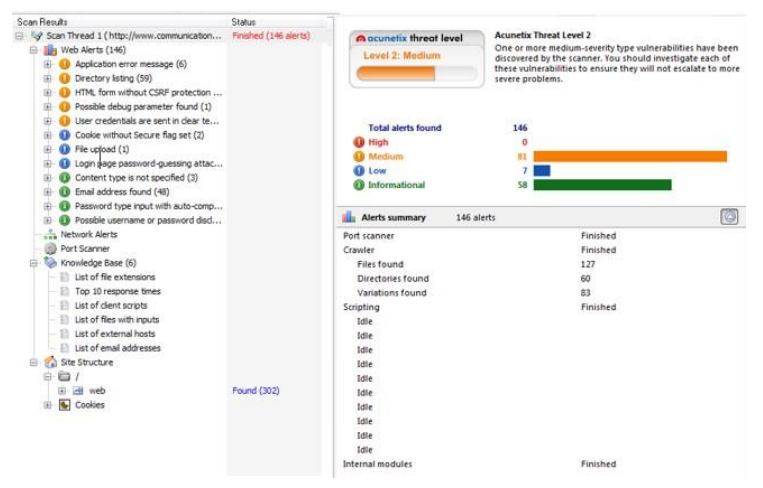

Gambar 10 Hasil pengujian security
Gambar 10 menunjukkan bahwa terdapat 146 peringatan yang terdiri dari 81 medium alert, 7 low alert, dan 58 informational alert. Hasil ini berarti aplikasi communication book dari aspek security berada pada kerentanan medium atau level 2 .

Pengujian usability menggunakan angket yang dikembangkan Lewis [27] yaitu Computer System Usability Questionnaire (CSUQ) kepada 30 responden di lingkungan SMPN 1 Selong yang terdiri dari guru, tenaga kependidikan, dan orang tua. Instrumen berupa angket menggunakan penilaian skala Likert dengan rentang nilai antara 1 sampai 5 . Skor 1 berarti tidak setuju, 2 berarti kurang setuju, 3 berarti ragu-ragu, 4 berarti setuju, dan 5 berarti sangat setuju. Skor penilaian yang diperoleh sebesar 2398 dari skor maksimal 2850 atau sebesar $84,14 \%$ yang dapat ditafsirkan bahwa tingkat kemudahan dan kepuasan penggunaan memiliki kategori sangat layak.

Pengujian portability menggunakan bantuan aplikasi BrowseEmAll untuk menjalankan beberapa browser secara virtual. Hasil pengujian menunjukkan bahwa aplikasi dapat berjalan dengan baik pada beberapa jenis browser yaitu Google Chrome, Mozilla Firefox, Safari 10, Opera, dan Internet Explore.

\subsection{Deployment}

Tahapan ini merupakan tahap akhir yakni menyebarkan produk aplikasi communication book agar dapat diakses secara online di mana dan kapan saja oleh pengguna. Aplikasi 
Infotek : Jurnal Informatika dan Teknologi

Vol. 5 No. 1, Januari 2022

Hal. 167-178

e-ISSN 2614-8773

DOI : 10.29408/jit.v5i1.4742

Link : https://dx.doi.org/10.29408/jit.v5i1.4742

dipublikasikan melalui alamat domain

[4] Bujang Rahman, "Kemitraan Orang Tua

http://communicationbook.web.id.

\section{Kesimpulan}

Berdasarkan hasil pengamatan yang dilakukan dari roses communication, planning, modelling, construction, dan deployment, dapat diambil kesimpulan sebagai berikut:

1. Karakteristik pengguna berada pada level penganut dini (early mayority).

2. Produk aplikasi communication book dapat berjalan dengan baik.

3. Produk aplikasi dapat memenuhi unsur inovasi, saluran komunikasi, waktu, dan sistem sosial.

4. Pengujian produk aplikasi communication book memenuhi semua kriteria standar ISO25010.

\section{Daftar Pustaka}

[1] L. Emerson, J. Fear, S. Fox, and E. Sanders, "Parental Engagement in Learning and Schooling: Lessons from Research a Report by the Australian Alliance for Children and Youth (ARACY) for the Family-School and Community Partnership Bureau.," Canberra, 2012.

[2] K. V. Hoover-Dempsey et al., "Why Do Parents Become Involved? Research Findings and Implications," The Elementary School Journal, vol. 106, no. 2, pp. 105-130, Nov. 2005, doi: 10.1086/499194.

[3] J. L. Epstein and F. L. van Voorhis, "More Than Minutes: Teachers' Roles in Designing Homework," Educational Psychologist, vol. 36, no. 3, pp. 181-193, Sep. 2001, doi: 10.1207/S15326985EP3603_4.

dengan Sekolah dan Pengaruhnya Terhadap Hasil Belajar Siswa," Jurnal Pendidikan Progresif, vol. 4, no. 2, pp. 129-138, 2014.

[5] N. Aedi and E. Rosalin, "Kerjasama Sekolah dan Masyarakat. Dalam T. D. UPI, Manajemen Pendidikan," in Manajemen Pendidikan, Bandung: Alfabeta, 2014, p. 280.

[6] H. Saragih, G. Gusvita, B. Reza, D. Setiyadi, and R. Akbar, "PENGEMBANGAN SISTEM INFORMASI DISTRIBUSI INFORMASI SEKOLAH MELALUI SMS GATEWAY DENGAN ZACHMAN FRAMEWORK," Jurnal Sistem Informasi, vol. 8, no. 1, p. 32, Oct. 2013, doi: 10.21609/jsi.v8i1.320.

[7] A. Silva, Á. Rocha, and M. P. Cota, "Electronic Booklet," International Journal of Information and Communication Technology Education, vol. 11, no. 4, pp. 97-108, Oct. 2015, doi: 10.4018/IJICTE.2015100107.

[8] E. M. Rogerd, Diffusion of Innovation, 5th ed. New York: Free Press, 2003.

[9] M. S. Raisinghani and A. Ramsaroop, "Information Systems Innovation: Diffusion and Implementation Issues," The Journal of Information Technology Theory and Application, vol. 1, p. 6, 1999.

[10] D. Heath, R. Maghrabi, and N. K. Carr, "Implications of Information and Communication Technologies (ICT) for School-Home Communication," Journal of Information Technology Education: Research, vol. 14, pp. 363-395, 2015, doi: $10.28945 / 2285$.

[11] Amirul Azuani Romle and D. Singh, "Integrated parent information system (SMIB) to increase parental involvement in children's learning process in Malaysian primary school," in Proceedings of the 2011 International Conference on Electrical Engineering and Informatics, Jul. 2011, pp. 1-6. doi: 10.1109/ICEEI.2011.6021593.

[12] N. Mia, "Child's Communication Book ConnectABILITY,"

http://connectability.ca/Garage/wpcontent/themes/connectability/plugin/work 
shops/offToSchool/off_to_school/skills/co mmunicate/pdf/CommunicationBook.pdf, 2010.

[13] S. Graham-Clay, "Communicating with Parents: Strategies for Teachers.," The School Community Journal, vol. 15, no. 1, pp. 117-129, 2005.

[14] M. Medina and J. Kenley, "Communication Between Family and School: Creating a Communication Notebook that Works," http://www.tsbvi.edu/outreach/2674communication-between-family-andschool-creating-a-communicationnotebook-that-works, Aug. 25, 2017.

[15] S. Sancoko, "Tinjauan kualitas informasi sistem pembelajaran e-learning scele.ui.ac.id (studi kasus: mahasiswa bidang administrasi program vokasi UI)," Jurnal Pendidikan Vokasi, vol. 7, no. 1, p. 87, Feb. 2017, doi: 10.21831/jpv.v7i1.11928.

[16] S. Suhartini, M. Sadali, and Y. Kuspandi Putra, "Sistem Informasi Berbasis Web Sma Al- Mukhtariyah Mamben Lauk Berbasis Php Dan Mysql Dengan Framework Codeigniter," Infotek: Jurnal Informatika dan Teknologi, vol. 3, no. 1, pp. 79-83, Feb. 2020, doi: 10.29408/jit.v3i1.1793.

[17] V. V. Parkar, P. Shinde, S. C. Gadade, and P. M. Shinde, "Utilization of Laravel Framework for Development of Web Based Recruitment Tool," 2017.

[18] R. Wardani, N. Y. Laksana, and I. B. Sutedja, "Pengembangan Media Pembelajaran Interaktif Wayang Berbasis Web untuk Pendidikan Kejuruan," in The 14th Seminar on Intelligent Technology And Its Application, 2013, pp. 244-250.

[19] J. W. Dearing, "Applying Diffusion of Innovation Theory to Intervention Development," Research on Social Work
Practice, vol. 19 , no. 5, pp. 503-518, Sep. 2009, doi: 10.1177/1049731509335569.

[20] J. W. DEARING, "Improving the State of Health Programming by Using Diffusion Theory," Journal of Health Communication, vol. 9, no. sup1, pp. 21-36, Jan. 2004, doi: 10.1080/10810730490271502.

[21] T. M. Somers, K. Nelson, and J. Karimi, "Confirmatory Factor Analysis of the EndUser Computing Satisfaction Instrument: Replication within an ERP Domain*," Decision Sciences, vol. 34, no. 3, pp. 595621, Aug. 2003, doi: 10.1111/j.15405414.2003.02428.x.

[22] B. Adams, E. S. Berner, and J. R. Wyatt, "Applying Strategies to Overcome User Resistance in a Group of Clinical Managers to a Business Software Application," Journal of Organizational and End User Computing, vol. 16, no. 4, pp. 55-64, Oct. 2004, doi: 10.4018/joeuc.2004100104.

[23] N. S. Sukmadinta, Metode Penelitian Pendidikan. Bandung: Remaja Rosdakarya, 2005.

[24] R. S. Pressman, Software Engineering A Practioner's Approach. New York: McGraw-Hill, 2010.

[25] S. Arikunto, Dasar - Dasar Evaluasi Pendidikan, Edisi Revisi, Cetakan kesebelas. Jakarta: Bumi Aksara, 2011.

[26] J. Akbar and A. Yaqin, "Sistem Informasi Rekam Medis Berbasis Web Pada Klinik Risa Rafana Menggunakan Metodologi Extreme Programming," Infotek: Jurnal Informatika dan Teknologi, vol. 4, no. 2, pp. 270-279, Jul. 2021, doi: 10.29408/jit.v4i2.3680.

[27] J. R. Lewis, "IBM computer usability satisfaction questionnaires: Psychometric evaluation and instructions for use," International Journal of Human-Computer Interaction, vol. 7, no. 1, pp. 57-78, Jan. 1995, doi: 10.1080/10447319509526110. 